\title{
MORBIDITY OF PEDIATRIC REFUGEES IN THE AREA OF PIRAEUS,
}

\section{GREECE}

E.K. Vouloumanou, T. Tsaprouni, G.N.Katsaras, V. MELIKOKJ, M.Binou, Z.Gerle, "TZANEIO" General Hospital of Piraeus, Pediatric Department, Athens, Greece.

\section{Background}

During the current European refugee crisis that started in 2015, Greece, and particularly the area of Piraeus, hosted a large population of refugees. Children refugees constituted a considerable proportion of this population.

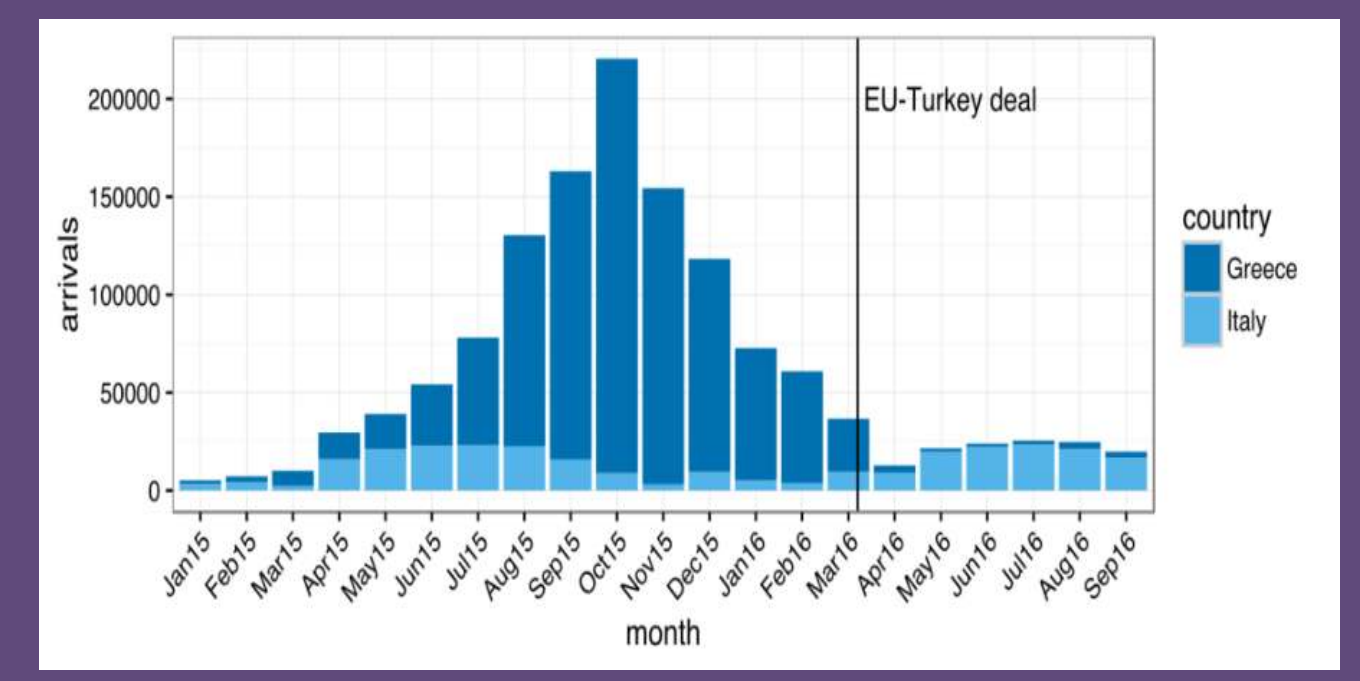

Figure 1. Arrivals through the Mediterranean sea to Greece and Italy from 01/01/2015 to 30/09/2016 (The UNHCR)

\section{Methods}

We prospectively recorded and evaluated the morbidity of pediatric refugees that presented in the pediatric emergency department (PED) with or without hospitalization, during one year period (01/10/2015-01/10/2016).

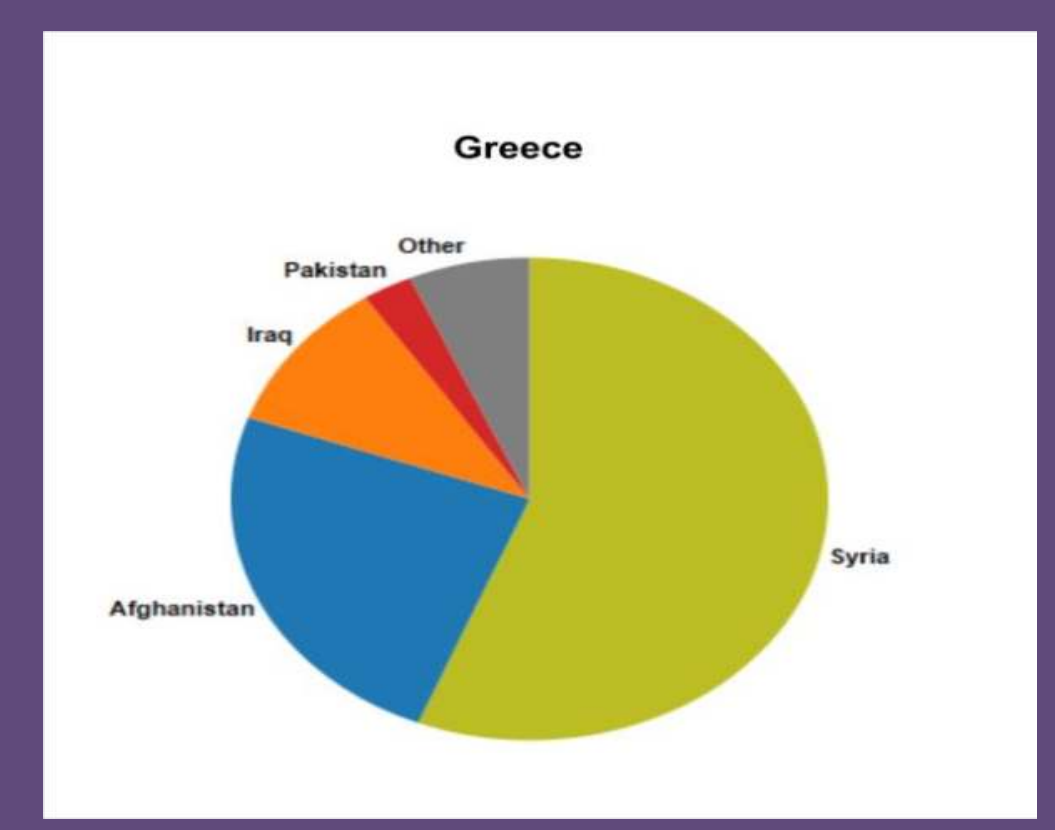

Figure 2. Ethnicities of refugees arriving in Greece though the Mediterranean sea (The UNHCR)

\section{Results}

A total of 93 children (mean age: 5 years, $71.2 \%$ male) were evaluated (Figure 4). The majority of them was Syrians (48.2\%), living in camps in the port of Piraeus (55.2\%) and reached the hospital by ambulance (46.1\%). Fever was the main reason of presentation at PED (36\%), followed by respiratory tract infections (17\%) and gastrointestinal infections (16\%). Personal and family medical records were unavailable.

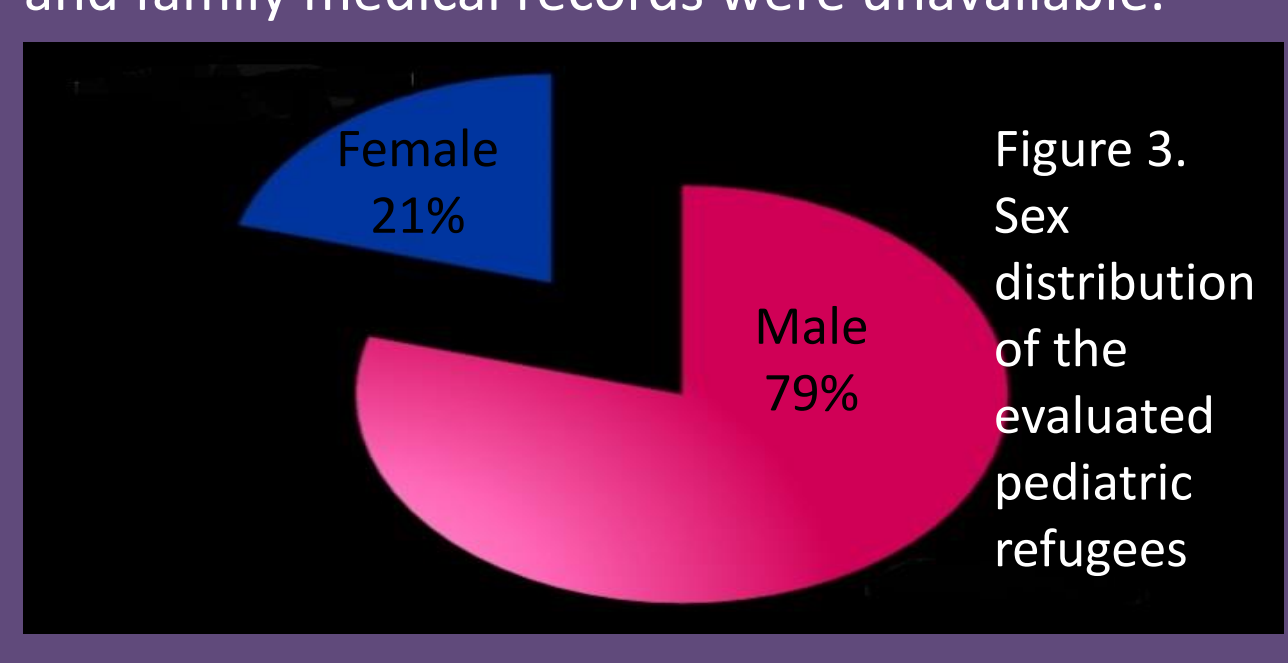

- No case of tuberculosis was identified. - One relapsing case of malaria from P. vivax due to initial treatment failure was noted. - Mean duration of hospitalization was 3.2 days.

-Antibiotics for common community-acquired bacteria were administered in $39.7 \%$. Follow up assessment was remarkably uncommon.

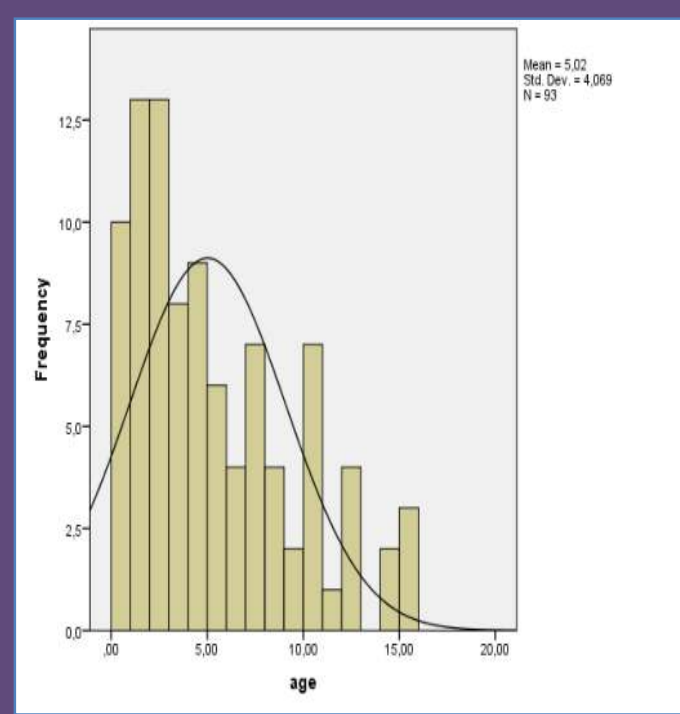

Figure 4. Age distribution of the evaluated pediatric refugees

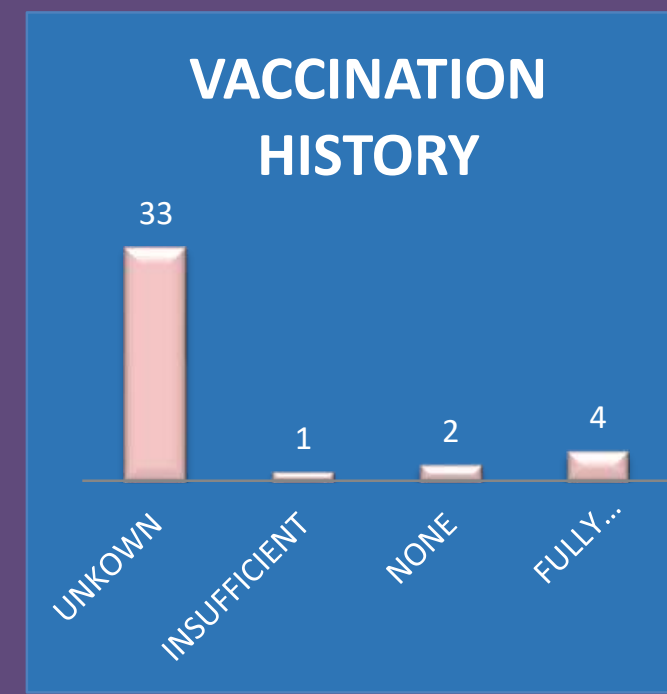

Figure 5. Vaccination history of the evaluated pediatric refugees

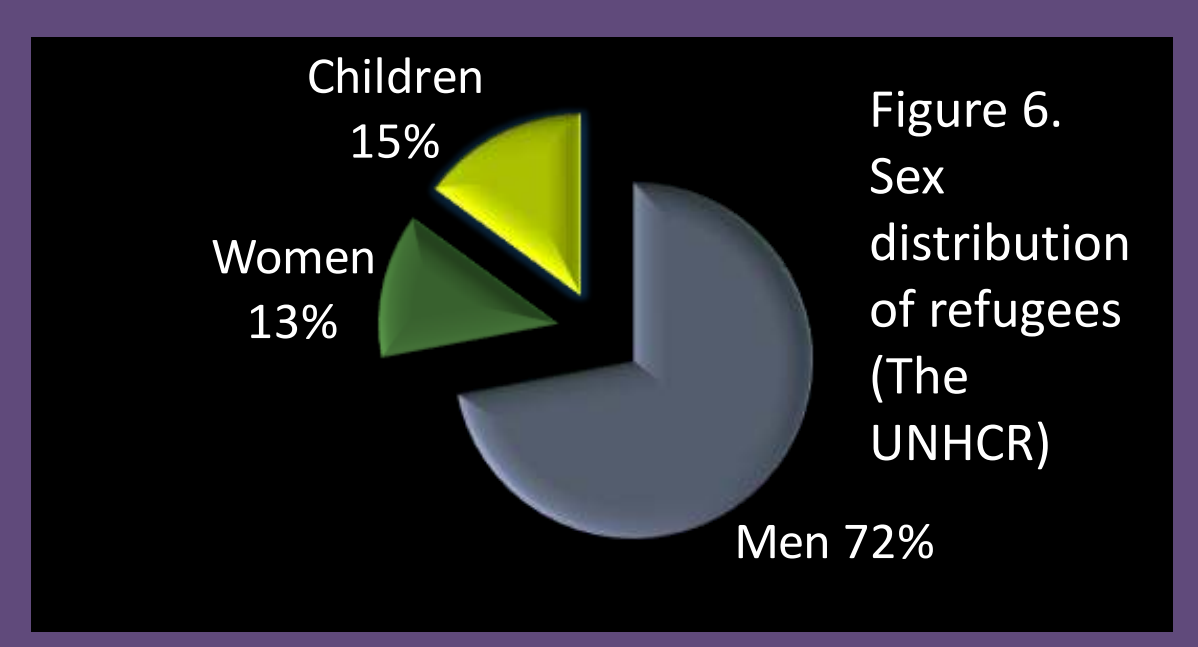

PERSONAL HISTORY

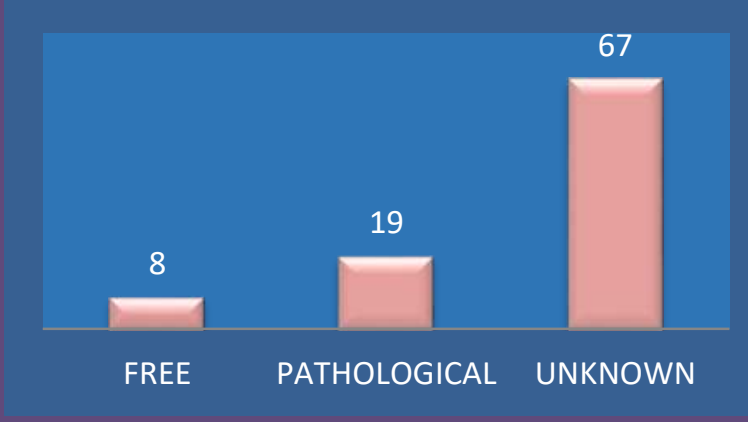

Figure 7. Personal history

of the evaluated pediatric refugees

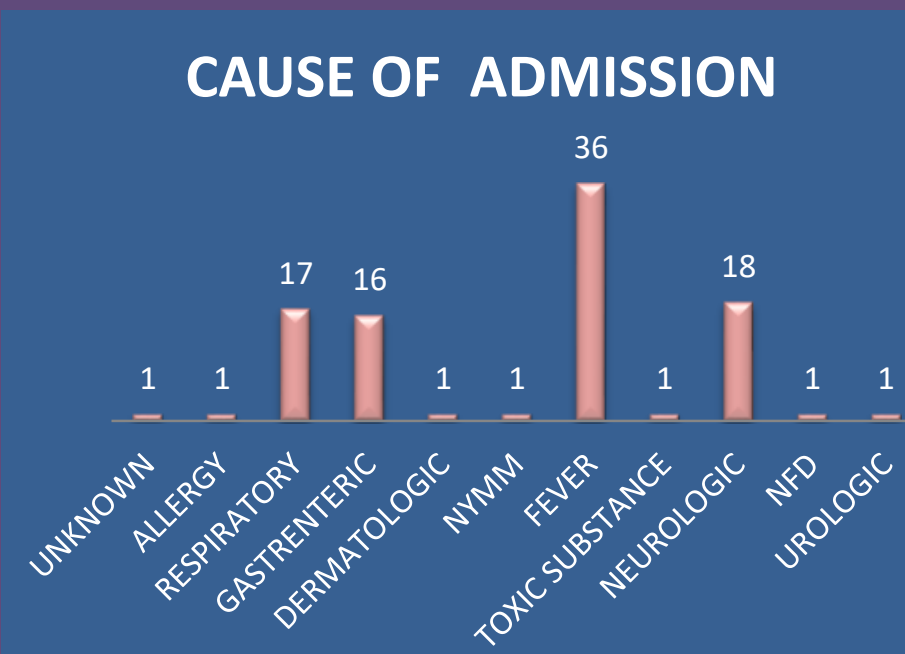

Figure 8. Cause of admission of the evaluated pediatric refugees

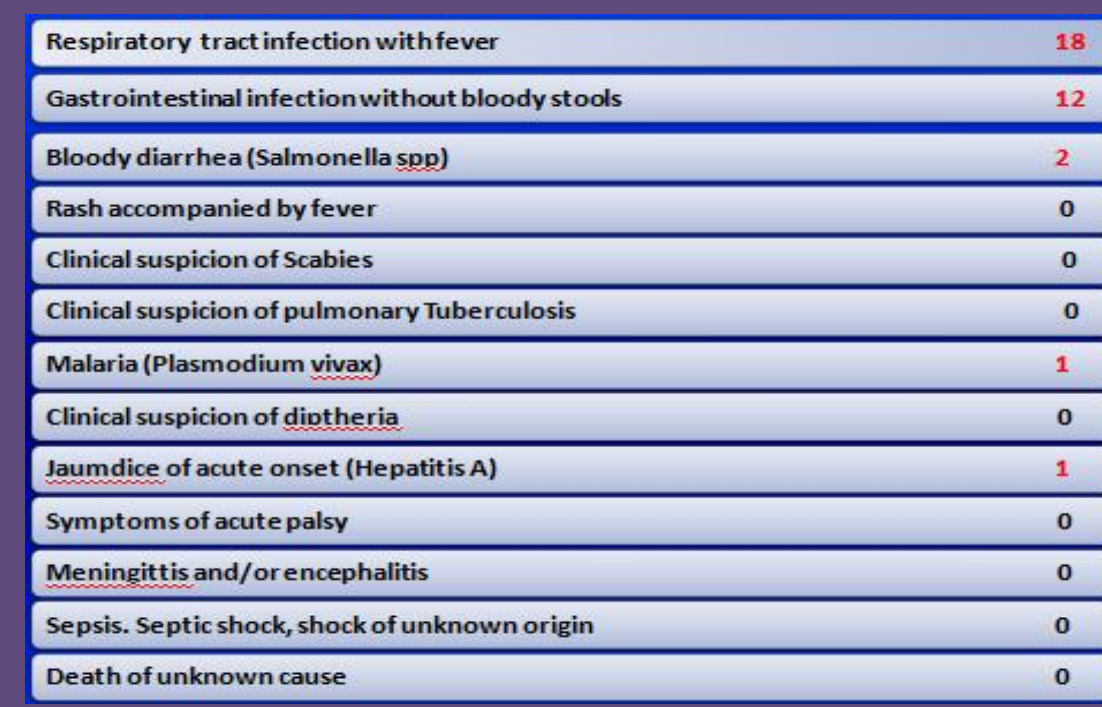

Figure 9. Identified diseases under the epidemiological surveillance of the Hellenic Center for Disease Control and Prevention

\section{Conclusion}

The evaluated children refugees had common community-acquired infections, received common antibiotic agents and had short length of hospitalization. $>$ The morbidity of the evaluated children refugees can be considered as similar to the common pediatric seasonal morbidity.

$>$ Of note, the majority of the evaluated patients were boys.
Expert Opinion : A statement by Dr Zsuzsanna Jakab, WHO Regional Director for Europe, 2 September 2015
In spite of a common perception that there is an association between migration and the importation of infectious diseases, there is no systematic association. Communicable diseases are primarily associated with poverty. Refugees and migrants are exposed mainly to the infectious diseases that are common in Europe, independently of migration. The risk that exotic infectious agents, such as Ebola virus or Middle East respiratory coronavirus (MERS-CoV), will be imported into Europe is extremely low, and experience has shown that, when it occurs, it affects regular travellers, tourists or healthcare workers rather than refugees or migrants.' Source: World Health Organization Regional Office for Europe. Population movement is a challenge for refugees and migrants as well as for the receiving population. [Internet]. Copenhagen: WHO; 2015.

